\title{
Gender Segregation in Occupation and Education in Kosovo
}

Theranda Beqiri, PhD Cand. SEEU

\author{
Lecturer, University "Haxhi Zeka”, Kosovo
}

Prof. Dr. Nasir Selimi

South East European University, R.Macedonia

Doi:10.5901/ajis.2015.v4n2p511

\section{Abstract}

\begin{abstract}
Inequality in labor market in Kosovo is persistent; the level of unemployment is highest in Europe. Unemployment rate is $35,1 \%$ and from this the level of unemployment for females is higher than males, with the highest level among females with low educational qualifications, primary and secondary and for unskilled. The aim of this paper is to present the level of segregation in education and also in occupation in Kosovo among the working population considering gender. Although there is an increasing level of females entering and finishing the education in each levels of education a gap between genders is still noticeable. The segregation in enrolment and graduation for females is still very concentrated in faculties of philosophy, philology, education, economics and medicine. Occupational segregation has the important role in gender inequality since it reduces the opportunities for females to be more concentrated to the jobs that are in the higher scale of the economy, we find that the main concentration of female employment are in education health and caring activities about $40 \%$ of employed women are in these sector's which is similar with other regional countries. Kosovo has also highest level of inactivity among the working force population from the latest LFS almost two-thirds of Kosovo's population is of working age (15-64 years). Of those who are working age, $63.1 \%$ are not economically active. Activity and employment rates tend to increase with education for both men and women.
\end{abstract}

Keywords: Gender, Segregation, Occupation, Education

\section{Introduction}

The aim of this paper is to present the level of segregation in education and also in occupation in Kosovo among the working population considering gender. Although there is an increasing level of females entering and finishing the education in each levels of education a gap between genders is still noticeable. The analysis is based on a research methodology combining extensive literature review whenever they are available, and with descriptive and analytical data from different reports and statistics.

The segregation in enrolment and graduation for females is still very concentrated in faculties of philosophy, philology, education, economics and medicine. Occupational segregation has the important role in gender inequality since it reduces the opportunities for females to be more concentrated to the jobs that are in the higher scale of the economy.

According to OSHA- EU segregation in occupations relates to the different work that men and women do as a consequence of their patterns of socialization, identifying tasks traditionally seen as 'women's work' or 'men's work'. Gender segregation in occupations is the tendency for men and women to be employed in different occupations across the entire spectrum of jobs.

The occupational segregation is caused by gender bias based on stereotypical, biological and social differences between men and women. The concentration of men and women in different kinds of jobs is known as occupational segregation.

The importance of segregation in education and then occupation is because it affects the gender inequality in labour market, by limiting the opportunities in being active in the labour market as whole. Since the evidence from the labour force surveys shows that the level of unemployment in Kosovo for females is around $12 \%$ higher than males $40 \%$ for females and 28,1 for males, the ones that are employed are segregated in 'women's occupations' . 


\section{Literature Review and Theoretical Evidence}

Human capital theory attributes gender segregation to lower education or skills of women. Gary Becker has argued that families invest less in the education of daughters than their sons leading to women's low skills (Becker 1981). Hence, discrimination starts even with pre-entering the labour market with caused barriers to education. Which than affects the productivity characteristics like motivation which workers bring with them to the market. Therefore according to Adnett (1996) gender differences in the distribution of domestic work may not only limit women's pre-entry investments in education but also affect their post education human capital formation and further contribute to their lower occupational attainment.

Women are not equally represented in all occupations and in all function levels. On the one hand women find themselves concentrated in a more limited number of occupations than men (horizontal segregation), and on the other hand they are present in larger numbers in lower function levels (vertical segregation).

According to Ehrenberg (2003) if occupational choices are directly limited, or if they are influenced by lower payoffs to given human capital characteristics, then occupational segregation certainly reflects labour market discrimination. Since the major consequence of occupational segregation is that it contributes significantly to the wage gap.

On the other hand labour market regulations have a positive impact on the quality of employment, and the degree of gender inequality within employment

According to (Anker 1997) we can see that factors from supply side factors may come from different decisions regarding human capital accumulation and family formation, and the supply side may come from the effects of taste and statistical discrimination, so they both are factors that determine occupational gender segregation

Many analyst focus on the fact that the process of globalization is also reducing the demand for unskilled and semi skilled workers, and that also new technologies may reduce the demand for labor as a whole and keeping the wages low (Carnoy, at al 1999)

Economically, occupational segregation matters for efficient allocation of the human resources. The persistence of gender stereotypes also has negative effects on education and training and thus causes gender-based inequalities to be perpetuated into future generations (Anker 1997)

\section{Segregation in Education in Kosovo}

The education system in Kosovo went through a lot of reforms and generally there has been an improvement in all levels, nevertheless there are still some concerns in the level of attainment and gender disparities

According to "Kosovo Education Strategic Plan (2011-2016)" closing the gross enrolment, completion and the gender gap particularly at the middle and higher end of the education cycle will depend on improving educational quality, ensuring equitable resource distribution and ensuring that there are no reasons for parents in poverty to restrict their children from education. Overall gender trends such as the gender parity index, enrolment ratios and percentage girls' enrolment figures suggest that the gender gap is gradually closing within the lower levels at schools but significantly widens in favor of boys as students move up the educational ladder

Table 1. Number of children, pupils and students in public and private education 2013/2014

\begin{tabular}{|c|c|c|c|c|c|c|c|c|c|}
\hline \multirow{2}{*}{ Level } & \multirow{2}{*}{ Education } & \multicolumn{2}{|c|}{ Total } & \multicolumn{2}{|c|}{ Fendes } & \multicolumn{2}{|c|}{ Males } & \multicolumn{2}{|c|}{ Dstrtution by gender in percentage } \\
\hline & & $\begin{array}{l}\text { No.d } \\
\text { pupls }\end{array}$ & Percentage & $\begin{array}{l}\text { Nood } \\
\text { pupis }\end{array}$ & Percentage & $\begin{array}{l}\text { No.d } \\
\text { pppiss }\end{array}$ & Percentage & Fenales & Males \\
\hline 0 & Preschool & 28768 & 5,8 & 12903 & 5,8 & 13835 & 5,8 & 48,3 & 51,7 \\
\hline $1+2$ & Primary and buer seconday & 200023 & 60.9 & 135602 & 60,7 & 145161 & 612 & 48,3 & 51,7 \\
\hline 3 & Upper secondary & 100437 & 21,8 & 46796 & 20,9 & 53641 & 226 & 48,6 & 53,4 \\
\hline $1+2$ & Primay and buer secondary specid & 635 & 0,1 & 259 & 0,1 & 376 & 02 & 40,8 & 59,2 \\
\hline 3 & Upper secondary special & 147 & 0,000 & 59 & 0,03 & 88 & 0,04 & 40,1 & 59,9 \\
\hline $5+6$ & Universty & 52159 & 11,3 & 27990 & 12.5 & 24220 & 10,2 & 53,6 & 48,4 \\
\hline & Total & 460969 & 100,0 & 223648 & 100,0 & 237321 & 100,0 & 48,5 & 51,5 \\
\hline
\end{tabular}

Source: Statistical Office Kosovo ; Education statistics 2013-2014 
The proportion of population in Kosovo is almost equally shared, Males: 50, 3\% and Females: 49,7 therefore we can say that the level of gap by gender in education is proportional when we refer to the statistical data. From the table 1 above we can see that the level of attainment of schools is higher for males compared to females, although the gap is narrowing from year to year. As it is shown the highest underrepresentation is in upper secondary school and in upper secondary special ${ }^{1}$, the level of females in all levels of education has increased and it is shown that tertiary education is the only level where females have the higher percentage of participation $51,5 \%$ compared $48,5 \%$ males.

Table 2. Number of students at the University of Prishtina in the academic year 2013/2014

\begin{tabular}{|l|r|r|r|}
\hline \multirow{2}{*}{ Faculty } & \multicolumn{3}{|c|}{ Total } \\
\cline { 2 - 4 } & Female & Male & Total \\
\hline Philosophy & 2717 & 1698 & 4415 \\
NMS & 2497 & 784 & 3281 \\
Philology & 2642 & 929 & 3571 \\
Law & 3016 & 2453 & 5469 \\
Economics & 5232 & 5763 & 10995 \\
Construction \& Architecture & 549 & 1587 & 2136 \\
Computer Engineering & 730 & 1669 & 2399 \\
Mechanical Engineering & 146 & 992 & 1138 \\
Medicine & 2806 & 1732 & 4538 \\
Arts & 344 & 297 & 641 \\
Agriculture & 263 & 892 & 1155 \\
Metallurgical Mining, Mitrovica & 210 & 389 & 599 \\
Physical Culture and Sports & 131 & 715 & 846 \\
Education & 3114 & 493 & 3607 \\
FATS Mitrovice & 204 & 424 & 628 \\
FATS Ferizaj & 160 & 301 & 461 \\
\hline Total & 24761 & 45879 \\
\hline & & \\
Source: UNIVERSITY OF PRISHTINA - CENTRAL ADMINISTRATION
\end{tabular}

Between the academic years 2000-2001 and 2009-2010, the number of university students almost doubled from 19,060 to 37,839 . No gender disparity exists in university enrollments World Bank (2012).

As we can see from the table 2 above this number increased to 45,879 by almost $8 \%$ in academic year 2013/2014 of the total students $54 \%$ were females at the University of Pristine. The most popular faculties are economics, law, philology, medicine, education and philosophy. Female students are segregated and overrepresented in education, philology, medicine and low, while men are segregated in agriculture, physical culture and sports, machinery, construction, architecture, computer engineering. There is a very little gender disparity in economics and arts, which are almost equal. As we can see from the education statistics described there is a high level of segregation on education for both females and males. Females are concentrated in education, administrative and carrying studies, while men are mostly concentrated in engineering, agriculture and sports. From graduated in Bachelor level degree in the academic year 2012/2013 at the University of Prishtina. Female make up 53 percent of the graduates. Female make up 44 percent of master's level graduates compared to 53 percent of female graduate studies in Bachelor Level. (Education Statistics 2013/2014)

During the years 2004- 2007 Labour force Surveys in Kosovo shows robust information on women and men participating in the labour market according to their educational level. The educated persons have more opportunities to be active in labour market. The higher the education the easier it seems to find a job and to maintain it.

1 Primary, lower secondary, upper secondary special are dedicated to children and youth with developmental difficulties. 
Table 3. Employed by sex and Education 2004-2007 (\%)

\begin{tabular}{|c|c|c|c|c|c|c|c|c|}
\hline year & \multicolumn{2}{|c|}{2004} & \multicolumn{2}{c|}{2005} & \multicolumn{2}{c|}{2006} & \multicolumn{2}{c|}{2007} \\
\hline Education & women & men & women & men & women & men & women & men \\
\hline Primary & 4 & 34 & 5 & 31 & 5 & 34 & 5 & 27 \\
\hline Secondary & 18 & 50 & 19 & 49 & 14 & 48 & 19 & 41 \\
\hline University & 75 & 83 & 64 & 82 & 61 & 79 & 65 & 80 \\
\hline
\end{tabular}

Source: Statistical Office Kosovo LFS, 2004-2007

\section{Gender Occupational Segregation in Kosovo}

Two kinds of gender segregation have been identified: horizontal segregation and vertical segregation. Horizontal segregation is where the workforce of a specific industry or sector is mostly made up of one particular gender. An example of horizontal segregation can be found in construction, where men make up the majority of the industry's workforce, whereas childcare is almost exclusively a female occupation.

Vertical segregation is where opportunities for career progression within a company or sector for a particular gender are narrowed. Vertical segregation affects women far more than men. For example, women are less likely to work as managers or senior officials than men.

Gender occupational segregation is an issue also in European countries, evidence from European Commission study, shows that considering all occupations, just $18 \%$ of women work in mixed occupations ( $60-40 \%$ men \& women), $69 \%$ in female-dominated occupations (>60\% female) and only $13 \%$ in male-dominated occupations ( $>60 \%$ male). In contrast, only $15 \%$ of male employees worked in mixed occupations and $59 \%$ in male-dominated occupations. This means more men- 26\%- work in occupations where they are a minority- that is female-dominated occupations. (European Commission 2014). While in OECD countries there are findings that irrespective of family commitments, many female professionals find it difficult to climb the career ladder. In fact, inequalities increase the higher up the pay scale you go, so that while on average in OECD countries women earn 16\% less than men, female top-earners are paid on average $21 \%$ less than their male counterparts. This suggests the presence of a so-called "glass ceiling". Women are also disadvantaged when it comes to decision-making responsibilities and senior management positions (OECD 2012)

In European countries segregation also applies by sector. Women have higher shares of total employment in the public services than in the private sector. Moreover, within almost all occupations, women have a higher share of the jobs in public services sectors compared to other industrial sectors. Public services sectors provide more opportunities for women in high-paid occupations, including as corporate managers and even in male-dominated occupations such as engineering and computing technicians than are available to women in private sectors (European Commission 2014).

In Kosovo examining the sectors in which people were employed in 2013, manufacturing, trade, education and construction employed almost half of employed people (Table 4). Manufacturing employed 12.6\%; trade 12.8\%; education employed $11.1 \%$ and construction employed $11.4 \%$ of employed people. Women were mostly employed in the education, social services and health sectors about $40 \%$ of employed women, where we can notice a horizontal segregation for females. Manufacturing, trade and construction are the most common employment sectors for men employing more than $40 \%$ of employed men, occupational segregation for males we can see from the table that there is no or very small segregation in wholesale and trade In Kosovo, financial and insurance activities, professional and scientific and technical activities .

The occupational segregation is in line with educational segregation for almost all of the occupations, for example the enrolment in economics was almost equal and the employment level in financial and insurance activities is equal.

Although it is interesting to emphasize that female have the higher percentage of employment in agriculture than males, and much lower percentage in enrolment in agricultural faculty, but maybe the reason is that they do work as the elementary employees not as skilled workers. 
Table 4. Employment by sector and gender (2013)

Sector employment shares (W)
Agricuture, forestry and fishing

- Includes undifferentiated goods and services-producing activities of private households for own use.

Source: Labour Force Survey 2013

In 2013 the majority of employed people held occupations of service and sales workers, elementary occupations, professionals and craft and trade workers Almost half of employed women were professionals and service and sales workers $30.1 \%$ were professionals and $16.1 \%$ were service workers. Men were more spread across occupations but the majority were employed in elementary occupations, service and sales, and crafts and related trades. It is interesting to see that among the professionals females had higher rate of employment than men, which usually is in line with the higher level of education.

Females also have double share of employment as clerks and technicians and associated professionals, but have much lower share of employment in higher positions as legislator, senior officials and managers, where is evident vertical segregation in occupations.

Table 5. Occupation of employment by gender 2013

\begin{tabular}{|c|c|c|c|}
\hline Kosovo 2013 & Male & Female & All \\
\hline \multicolumn{4}{|l|}{ EMPLOYMENT BY OCCUPATIONAL CATEGORY ('000S) } \\
\hline Legislators, senior officials and manajers & 19.9 & 3.8 & 23.7 \\
\hline Professionds & 30.6 & 23.5 & 54.1 \\
\hline Technicians and associated professionals & 17.4 & 9.5 & 26.9 \\
\hline Clerks & 9.6 & 5.5 & 15.1 \\
\hline Service workers and shop and market soles workers & 45.9 & 126 & 58.5 \\
\hline Skilled agricutural and fishery workers & 7.4 & 20 & 9.4 \\
\hline Cratt and related trade workers & 47.3 & 8.0 & 55.3 \\
\hline Plant and machine operators and assemblers & 241 & 13 & 25.4 \\
\hline - Elementary coccupations & 61.5 & 119 & 73.6 \\
\hline Total & 264.1 & 78.0 & 342.1 \\
\hline \multicolumn{4}{|l|}{ OCCUPATION EMPLOYMEAT SHARES (S) } \\
\hline Legislators, senior officials and managers & 7.5 & 4.9 & 6.9 \\
\hline Professiond's & 116 & 301 & 15.8 \\
\hline Technicians and associated professionals & 6.6 & 122 & 79 \\
\hline Clerks & 3.7 & 70 & 44 \\
\hline Service wodkers and shop and market sales workers & 17.4 & 16.1 & 17.1 \\
\hline Skilled agricutural and fishery wodkers & 28 & 2.5 & 27 \\
\hline Cratt and related trade workes & 179 & 10.3 & 16.2 \\
\hline Plant and machine operators and aseemblers & 9.1 & 17 & 7.4 \\
\hline Elementary ccoupations & 233 & 153 & 215 \\
\hline Total & 100.0 & 100.0 & 100.0 \\
\hline
\end{tabular}

Source: Labour Force Survey 2013 
According to the LFS 2009 the main employer of females was public sector with $57 \%$ of the whole share of employment , private sector $23 \%$ followed by the publicly owned enterprises 10\% and self-employed and NGO;s this is similar with other European countries with the higher share of females working in public sector than in private sector.

Higher share of females is maybe due to the more security considering working contracts on the job and the application of labour law of Kosovo and social security.

Since from some studies there is an indication that a large share of private companies do not

even provide their workers with such basic benefits as maternity leave, paid annual leave, paid sick leave, and unpaid leave (World Bank 2012).

\section{Conclusion and Recommendations}

From the evidence in this paper we can conclude that there is a high level of educational segregation by gender in Kosovo which reflects also the occupational segregation in sectors and professions. Females are segregated in Female students are segregated and overrepresented in education, philology, medicine and low, while men are segregated in agriculture, physical culture and sports, machinery, construction, architecture, computer engineering. There is a very little gender disparity in economics and arts. Therefore, females are mostly employed in the education, social services and health sectors about $40 \%$ of employed females, where we can notice a horizontal segregation for females. We found also that females have a share in employment as professionals which are a step forward and it might give better opportunities for females. While males, were disproportionally concentrated in manufacturing, trade and construction occupations.

There is some mixture in employment in both genders in wholesale and financial institutions, which is consistent with educational patterns in Kosovo. We also found that the biggest share of employment of females is in public sector and publicly owned enterprises, $67 \%$ and only $23 \%$ in private sector, which is consistent with European countries, although not in level of participation in public sector. Even though there is a very high level of unemployment level in Kosovo, especially for females $40 \%$ we can see that with higher education unemployment is decreasing, together with participation rate in labour market.

\section{Recommendations}

- There is a high level of occupational segregation in education and in occupations as health and caring activities in Kosovo, policy maker should take it more seriously and enforce the labour low also in private sector to be fulfilled, therefore the shares of females may be distributed more evenly through all the sectors.

- Although there were some progress in education regarding gender, to further improve education policies and expanding opportunities for different professions regarding gender, in order to decrease gender inequality and participation in labour market.

- Increasing awareness of importance in participating in labor markets for females, so they can have a chance in employment through governmental policies and employment offices.

- Monitoring of implementation of labor low and discrimination laws regarding gender, on implementation of paid maternity leave, paid annual leave and paid sick leave.

- Increasing the level of vocational training centers with different patterns of professional trainings.

- Another issue that needs to be addressed by policy makers in order to improve gender opportunities is to argument provisions for childcare for children until the age of primary school.

- There is no data for wages in Kosovo, which will show is there a gender inequality in payment, therefore there is a need for disaggregated data on wages.

\section{References}

Adnett, Nick;' European Labour Market, Analysis \& Policies' ; Addison Wesley Longman, 1996

Anker, Richard. 1997. "Theories of Occupational Segregation by Sex: An Overview."International Labor Review, 136(3): 315-339.

Becker. S Gary.; Economica, 1981, 48(189), pp. 1-15"Altruism in the Family and Selfishness in the Market Place. http://www.jstor.org/ stable/2552939

Becker . S Garyr; Cambridge 1981 'A Treatise on the Family'; , Mass.: Harvard University Press 0. 6490

Blau, Francine D., Peter Brummund, and Albert Yung-Hsu Liu. 2013. "Trends in Occupational Segregation by Gender 1970-2009: Adjusting for the Impact of Changes EhrenbergG, Smith S ; Modern Labour Economics, Theory and Policy: Addison Wesley 2003 Pearson Education 
Brendan Burchell, Mr Vincent Hardy, Professor Jill Rubery and Dr Mark Smith2014 'A New Method to Understand Occupational Gender Segregation in European Labour Markets' ;, ISBN 978-92-79-44696-2 doi: 10.2838/748887 @ European Union, 2014 European Commission - Directorate-General for Justice,

Carnoy, M., Hallak, J., \& Caillods, F. (1999). Globalization and educational reform: what planners need to know (pp. 13-37). Unesco, International Institute for Educational Planning.

Rolf Becker Eur Sociol Rev (2003) 19 (1): 1-24 doi:10.1093/esr/19.1.1"Educational Expansion and Persistent Inequalities of Education: Utilizing Subjective Expected Utility Theory to Explain Increasing Participation Rates in Upper Secondary School in the Federal Republic of Germany"

Ulf Färnsveden, Ariana Qosaj - Mustafa, Nicole Farnsworth April2014, 'Kosovo Country Gender Profile; Analysis of gender differences at all levels in Kosovo ": Orgut Consulting, financed by Embassy of Sweden.

Kosovo Agency of Statistics "Results of the Labour Force Survey 2009", Social Statistics Department Labour Market Sector.

Kosovo Agency of Statistics "Results of the Labour Force Survey 2012", Social Statistics Department Labour Market Sector.

Kosovo Agency of Statistics "Results of the Labour Force Survey 2014", Social Statistics Department Labour Market Sector.

Kosovo Agency of Statistics "Results of the Labour Force Survey 2004-2007, Social Statistics Department Labour Market Sector.

Ministry of Education Science and Technology "Kosovo Education Strategic Plan (2011-2016)" http://www.masht-gov.net/advCms/ documents/KESP_2011_2016.pdf

Organisation for Economic Co-operation and Development, OECD 2012 'Gender Equality in Education,Employment and Entrepreneurship: Final Report' to the MCM 2012C/MIN(2012)5

Statistical Office Kosovo ; Education statistics 2013-2014

World Bank (2012) Kosovo: Gender Gaps in Education, Health and Economic Opportunities Poverty Reduction and Economic Management Unit Europe and Central Asia Region

OSHA_EU , Web-site https://osha.europa.eu/en/faq/women-and-health/what-does-2018gender-segregation-in-occupations2019-mean 
